\title{
A validation of the use of names to screen for risk of chronic hepatitis B in Victoria, Australia, 2001 to 2010
}

J H MacLachlan (jennifer.maclachlan@mh.org.au) ${ }^{1,2}$, Y J Wang ${ }^{3}$, B C Cowie ${ }^{1,3,4}$

1. World Health Organisation Regional Reference Laboratory for Hepatitis B, Victorian Infectious Diseases Reference Laboratory, Victoria, Australia

2. Department of Medicine, University of Melbourne, Victoria, Australia

3. Burnet Institute, Victoria, Australia

4. Victorian Infectious Diseases Service, Royal Melbourne Hospital, Victoria, Australia

Citation style for this article:

MacLachlan JH, Wang YJ, Cowie BC. A validation of the use of names to screen for risk of chronic hepatitis B in Victoria, Australia, 2001 to 2010 . Euro Surveill. 2013;18(47):pii=20638. Available online: http://www.eurosurveillance.org/ViewArticle.aspx?Articleld=20638

The burden of chronic hepatitis B (CHB) is increasing in Australia, particularly in those born in the Asia-Pacific region, and nearly half are undiagnosed. Primary care clinicians have a key role in diagnosing $\mathrm{CHB}$, however identification of patients at risk is hindered by lack of awareness and limited information on country of birth in patient records. This study evaluates the potential of a validated list of names associated with Asian country of birth as a screening tool to predict risk of $\mathrm{CHB}$, by comparing it with surveillance records for all people diagnosed with CHB or salmonellosis in Victoria from 2001 to 2010, and analysed using standard screening tools. Name list match was associated with CHB notification, with over $60 \%$ of cases having one name matching the list (sensitivity), and nearly one third matching both given name and surname; less than $15 \%$ and $2 \%$ of salmonellosis notifications matched for one name and both names, respectively (false positives). These results show that more than half of notified cases of CHB would have been identified by this name list, and that it could be used in support of initiatives to improve diagnosis of patients with diseases associated with country of birth when limited information is available.

\section{Introduction}

The global prevalence of chronic hepatitis B (CHB) has been estimated at 350 million people, with the greatest burden amongst those living in Asia and the Pacific [1]. Despite comprising only around $5 \%$ of the Australian population [2], migrants from the Asia-Pacific region represent nearly $40 \%$ of estimated 218,000 Australians living with $\mathrm{CHB}[3,4]$. Without treatment, $15-40 \%$ will suffer serious complications of liver disease [5] including primary liver cancer, the fastest increasing cause of cancer mortality in Australia [6].

Early detection of CHB enables positive interventions for individual patients and the wider community. Effective antiviral treatment can significantly reduce the complications of chronic infection such as cirrhosis and hepatocellular carcinoma (HCC) [6,7], and diagnosis in an individual facilitates screening and vaccination of susceptible contacts. Such screening and treatment initiatives have been demonstrated to be cost-effective $[8,9]$. Clinical guidelines recommend routine screening for those born in intermediate (2-8\%) and high ( $>8 \%)$ CHB prevalence countries $[5,10]$, however undiagnosed CHB is common $[11,12]$. It has recently been estimated that $45 \%$ of those living with CHB in Australia have not been diagnosed [3].

The need for improved identification and management of CHB in the primary healthcare setting is well recognised [13], however, the lack of information on country of birth in patient records in Australian general practices is a substantial barrier to systematic identification of those most at risk [14]. Improving recording of country of birth is important, and educating clinicians in which patients should be routinely offered testing is a key consideration [15]. However, it is likely that further decision support and prompting regarding testing for hepatitis B virus (HBV) is necessary, given the existing large number of undiagnosed Australians with CHB despite these recommendations and education programmes that have been in place for years.

The linking of country of birth to patient name is a method that has previously been used for determination of ethnicity using a list of names derived from census records, and has been shown to be predictive of country of birth for both Hispanic [16] and Asian American [17-19] patients. In addition, clinical indicators (such as body mass index) were similar between self-identified and name list-identified groups, suggesting that this method identified a representative sample of the population within each ethnicity [19].

In addition, software tools such as Nam Pehchan and OnoMAP have been used in the United Kingdom to assign ethnicity based on names for notified cases of CHB [20] and cancer registry records [21]. However, 
there has been no examination of this approach in the Australian context, nor, to our knowledge, has there been an assessment of the utility of a name list as a screening tool for risk of having a chronic communicable disease associated with birth country.

This analysis aimed to determine whether a considerable proportion of people attending general practices would be effectively identified using a name list as a screening tool, by examining the sensitivity and specificity of the name list when compared with notifications. More broadly, this study aimed to bridge the gap in evidence and evaluate the utility of the name list in identifying risk of CHB associated with country of birth, to promote and support systematic diagnosis in general practice.

\section{Methods}

\section{Asian-Pacific name list}

The list of names used in this analysis was derived in the United States from Social Security and Medicare administration records containing country of birth information on a pool of over 400 million applicants, with the original aim of creating a method for classification of ethnicity within the broad group of Asian Americans (the full process of which is described in reference [17]).

Individual name lists were derived for the six major Asian ethnic groups in the United States: Chinese (including those from Hong Kong and Taiwan), Japanese, Filipino, Korean (North and South), Indian and Vietnamese. Names were chosen for inclusion on the basis of their predictive quality, based on association with the specific country of birth and frequency, i.e. names were only included if the majority of people of a certain name were associated with a given origin, and names occurring less than five times were excluded.

The full list contains a total of 20,693 unique names, each associated with a specific country of birth but aggregated for the purpose of this analysis as predictive of birth in any of the countries included.

\section{Data matching: surveillance notifications}

Infection with HBV is notifiable to the Department of Health in Victoria, with notification including limited patient demographic and disease information required of both the diagnosing clinician and laboratory within five days [22]. Notifications are reported as either newly acquired (acute infection) or unspecified (chronic infection) according to patient history and serological evidence. The case definition for hepatitis B notification in Australia requires detection of hepatitis $B$ surface antigen (HBsAg) or hepatitis B DNA, with acute infections differentiated by the presence of high levels of IgM to hepatitis B core antigen (anti-HBC) and/or demonstrated absence of prior infection [23].
TABLE 1

Screening test construct for name list analysis

\begin{tabular}{|l|l|}
\hline Sensitivity & $\begin{array}{l}\text { Proportion of chronic hepatitis B } \\
\text { notifications with a name match }\end{array}$ \\
\hline Specificity & $\begin{array}{l}\text { Proportion of salmonellosis } \\
\text { notifications without a name match }\end{array}$ \\
\hline Positive predictive value & $\begin{array}{l}\text { Proportion of matches that were } \\
\text { chronic hepatitis B notifications }\end{array}$ \\
\hline Negative predictive value & $\begin{array}{l}\text { Proportion of non-matches that } \\
\text { were salmonellosis notifications }\end{array}$ \\
\hline
\end{tabular}

Notification data for $\mathrm{CHB}$ were extracted from the Victorian Notifiable Infectious Disease Surveillance (NIDS) database by staff from the Communicable Diseases Prevention and Control Unit, Department of Health, Victoria, and compared with the name list to produce a de-identified dataset with a variable indicating a name match. Notified cases of salmonellosis were subjected to the same matching procedure with the name list and used as a control group. Salmonellosis is an acute gastroenteritis with a short incubation period and no particular association with country of birth [24].

Records were assessed for completeness in reporting, and basic demographic characteristics (median age, sex ratio, proportion born overseas) analysed for both diseases.

To determine the effectiveness of the list for the identification of persons at risk of $\mathrm{CHB}$, we tested the name list as a screening tool (see Table 1). Notification data were used as the source of diagnosed cases, with notifications for $\mathrm{CHB}$ representing true positives, and notified cases of salmonellosis representing true negatives (analogous to a gold standard diagnostic test); the presence of a name matching the supplied list in a given case was considered a positive result in the screening test. This construct was used to calculate sensitivity and specificity of the name list when using an algorithm that matched both given name and surname ('match both') and one that matched either given name or surname ('match either').

As the positive and negative predictive values (PPV and NPV) of a screening tool are dependent on the prevalence of disease in the target population, and the sample of notifications used here included roughly equal numbers of hepatitis $B$ and salmonellosis notifications, PPV and NPV needed to be adjusted to the prevalence of hepatitis $B$ that would be expected in the screened population. CHB prevalence has been demonstrated in a recent serosurvey to vary considerably by geographic region, largely related to the proportion of residents who were born in endemic areas [25]. Estimates of $1.5 \%$, $3 \%$ and $6 \%$ prevalence were selected to reflect the expected number of people living with $\mathrm{CHB}$ attending 
a clinical practice within a general, moderate and high prevalence area, respectively. Adjusted PPV and NPV values were calculated using the following formulae:

$$
\begin{aligned}
& P P V=\frac{\mathrm{Se} * \mathrm{Pr}}{(\mathrm{Se} * \mathrm{Pr})+(1-\mathrm{Sp})(1-\mathrm{Pr})} \\
& N P V=\frac{\mathrm{Sp} *(1-\mathrm{Pr})}{(\mathrm{Sp} *(1-\mathrm{Pr}))+(1-\mathrm{Se})(\mathrm{Pr})}
\end{aligned}
$$

where Se is sensitivity, Sp is specificity, and $\mathrm{Pr}$ is prevalence.

\section{Statistical analysis}

Sensitivity was estimated according to the 'match either' algorithm by sex, age group and across the time period of notifications used. For those notifications where country of birth information was available, sensitivity measures were calculated individually for each of the six name list countries, as well as for the 10 most commonly identified countries of birth that were not originally used to develop the name list.

The chi-square test was used to test the significance of differences in sensitivity according to notification type (CHB compared to salmonellosis), sex, age group, year of notification, as well as differences in country of birth reporting according to sex and presence of name list match. The Wilcoxon rank sum test was used to evaluate differences in age distribution between groups. Exact binomial 95\% confidence intervals $(\mathrm{Cl})$ were calculated around screening test measures. Data were handled and graphically presented using Microsoft Excel, with statistical analyses conducted using Stata 11.

\section{Ethics}

Ethical approval for this research was granted by the Royal Australian College of General Practitioners' National Research and Evaluation Ethics Committee as a component of a broader study (NREEC $10-011$ ).

\section{Results}

Between 2001 and 2010, there were 17,438 notifications of chronic HBV infection to the Victorian Department of Health, and 14,865 notifications for salmonellosis infection. Notifications differed in age distribution according to disease, with those diagnosed with salmonellosis generally younger (median age 25 years (interquartile range (IQR): 8-45 years) compared with 35 years (IQR: 27-46 years) for HBV, p<0.001) and less likely to be male $(47.7 \%$ of salmonellosis cases were male, compared with $54.2 \%$ of CHB cases, p<0.001).

The majority of notifications for salmonellosis (83\%) were patients born in Australia; however despite representing only around a quarter of the total Victorian population [26], those born overseas made up the vast majority (91\%) of CHB notifications. Completeness of this information was similar for salmonellosis and CHB, with greater than $99 \%$ of notifications reporting sex and age of cases, but less than one in five recording country of birth.

The sensitivity of the name list varied substantially depending on the type of match assessed (Table 2). While around $60 \%$ of those with a notification for CHB had either a given name or a surname matching the name list, just under one third had both names matching the list. In contrast, less than $15 \%$ and $2 \%$ of salmonellosis notifications matched one name and both names, respectively ( $p<0.001$ for both comparisons).

Specificity was correspondingly higher for matching both names instead of either name; in those with salmonellosis notification (i.e. not at increased risk of (HB), only $1.8 \%$ of persons were identified as being at risk based on this name list (specificity of 98.2\%). This proportion, a measure of false positives, increased to nearly $15 \%$ when matching either given name or surname (specificity decreased to $86.4 \%$ ).

The differing sensitivity and specificity values for the two types of match are reflected in the positive and negative predictive values, with a patient who matched both names much more likely to have a diagnosis of CHB than one who matched either name (PPV in a high prevalence population $51.8 \%$ for both names, compared with $22.3 \%$ for either name). The inverse was true for the NPV, which increased with improving sensitivity; however, the difference was much less marked, with the proportion of non-matches who were not $\mathrm{CHB}$ (true negatives) only increasing from 95.7 to $97.2 \%$ when matching either name instead of both (Table 2 ).

As expected, PPV was heavily impacted by reduced $\mathrm{CHB}$ prevalence. Using an average $\mathrm{CHB}$ prevalence (1.5\%), PPV was calculated to be $6.39 \%$ for matching either name and $20.4 \%$ for matching both, while using moderate prevalence resulted in PPV values of $12.2 \%$ (match either) and $34.2 \%$ (match both). As expected, PPV was greatest in high prevalence areas, at $22.3 \%$ (match either) and $51.8 \%$ (match both). Prevalence had little impact on NPV, with all estimates above $95 \%$ regardless of $\mathrm{CHB}$ prevalence or match type (see Table 2).

Although demonstrating no trend over time (data not shown), the sensitivity of the name list differed substantially by age group, being only $33.6 \%$ in those younger than 10 years compared with $61.0 \%$ in those aged 10 years or older ( $p<0.001$, Figure). Sensitivity was also slightly higher in women $(62.3 \%$ compared with $59.5 \%$ in men, p<0.001).

The sensitivity of the name list varied substantially by country of birth. The vast majority (over 96\%) of those with CHB born in China and Vietnam were identified 
Sensitivity, specificity, and positive and negative predictive values based on estimated prevalence of chronic hepatitis $\mathrm{B}$, by type of match, Victoria, 2001-2010 ( $n=32,303)$

\begin{tabular}{|c|c|c|c|c|}
\hline & \multicolumn{2}{|c|}{ Both surname and given names } & \multicolumn{2}{|c|}{ Either surname or given name } \\
\hline $\begin{array}{l}\text { Number of } \mathrm{CHB} \text { cases matching list } \\
\text { Sensitivity }(95 \% \mathrm{Cl})\end{array}$ & \multicolumn{2}{|c|}{$\begin{array}{c}5,279 \text { of } 17,438 \\
30.3 \%(30.0-31.0 \%)\end{array}$} & \multicolumn{2}{|c|}{$\begin{array}{c}10,594 \text { of } 17,438 \\
61.0 \%(60.0-61.5 \%)\end{array}$} \\
\hline $\begin{array}{l}\text { Number of salmonellosis cases not matching list } \\
\text { Specificity }(95 \% \mathrm{Cl})\end{array}$ & \multicolumn{2}{|c|}{$\begin{array}{c}14,598 \text { of } 14,865 \\
98.2 \%(98.0 \neg-98.4 \%) \\
\end{array}$} & \multicolumn{2}{|c|}{$\begin{array}{c}12,847 \text { of } 14,865 \\
86.4 \%(85.9-87.0 \%)\end{array}$} \\
\hline Prevalence of $\mathrm{CHB}$ & PPV & NPV & PPV & NPV \\
\hline $1.5 \%$ & $20.4 \%$ & $98.9 \%$ & $6.39 \%$ & $99.3 \%$ \\
\hline $3.0 \%$ & $34.2 \%$ & $97.9 \%$ & $12.2 \%$ & $98.6 \%$ \\
\hline $6.0 \%$ & $51.8 \%$ & $95.7 \%$ & $22.3 \%$ & $97.2 \%$ \\
\hline
\end{tabular}

CHB: chronic hepatitis $\mathrm{B}$; $\mathrm{Cl}$ : confidence interval; NPV: negative predictive value; PPV: positive predictive value.

as matching either name on the list, and these two countries alone made up around three quarters of total CHB notifications with a name list match. Sensitivity was moderate for those born in Korea (76.0\%), India $(60.4 \%)$ and the Philippines (48.5\%), as well as AsiaPacific countries not originally used to derive the name list, such as Malaysia, Singapore, East Timor and Laos (Table 3).

Analysis of factors potentially associated with the country of birth not being reported in the notification dataset found no difference according to sex; however those with no country of birth recorded were on average older, and more likely to have a name matching the list than those with a country of birth recorded (sensitivity of $39.5 \%$ compared with $32.7 \%$, p<0.001, Table 4 ).

\begin{abstract}
Discussion
When assessed as a screening tool, the name list evaluated here detected the majority $(61 \%)$ of the 17,438 notified cases of CHB in Victoria, Australia between 2001 and 2010. Sensitivity and PPV were highest when either name was matched, at the cost of reduced specificity and NPV. Predictive values varied according to the estimated prevalence of CHB among primary care practices. Women and those in older age groups with CHB were more likely to match the name list, and the list was most sensitive for those born in Vietnam and China, with moderate sensitivity for other name list and a number of non-name list countries.
\end{abstract}

\section{FIGURE}

Proportion of chronic hepatitis B notifications matching name list (either surname or given name) by age group, with 95\% confidence intervals $(n=20,693)$

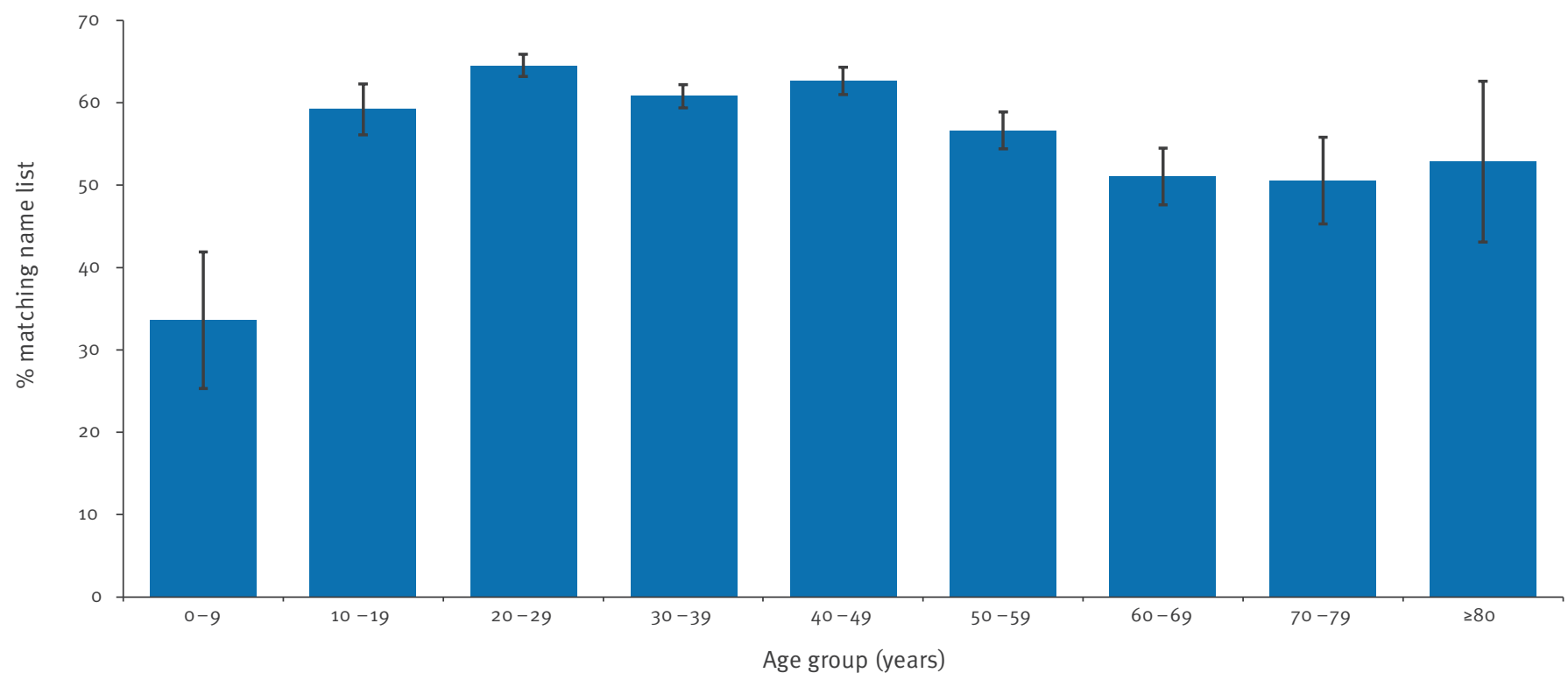


TABLE 3

Proportion of chronic hepatitis B notifications matching name list (either surname or given name), by country of birth, Victoria, 2001-2010 (n=2,167)

\begin{tabular}{|c|c|c|c|c|}
\hline Country of birth & $\begin{array}{l}\text { Number of } \mathrm{CHB} \\
\text { notifications }\end{array}$ & $\begin{array}{c}\text { Number of } \mathrm{CHB} \\
\text { notifications matching list }\end{array}$ & $\begin{array}{c}\text { Proportion matching } \\
\text { name list ('sensitivity') }\end{array}$ & $\begin{array}{l}\text { Proportion of total CHB } \\
\text { notifications with match } \\
\qquad(\mathrm{n}=1,584)\end{array}$ \\
\hline China $^{a}$ & 690 & 665 & $96.4 \%$ & $42.3 \%$ \\
\hline Vietnam & 351 & 339 & $96.6 \%$ & $21.4 \%$ \\
\hline Philippines & 99 & 48 & $48.5 \%$ & $3.04 \%$ \\
\hline Korea $^{a}$ & 76 & 58 & $76.0 \%$ & $3.67 \%$ \\
\hline India & 53 & 32 & $60.4 \%$ & $2.02 \%$ \\
\hline Japan & $<5^{b}$ & $<5^{b}$ & $100 \%$ & $<0.32 \%$ b \\
\hline TOTAL (name list ${ }^{\mathrm{b}}$ ) & 1,269 & 1,142 & $90.0 \%(1,142)$ & $72.62 \%(1,150)$ \\
\hline Australia & 255 & 60 & $23.5 \%$ & $3.85 \%$ \\
\hline Malaysia & 76 & 51 & $67.1 \%$ & $3.23 \%$ \\
\hline Burma & 122 & 42 & $36.9 \%$ & $2.85 \%$ \\
\hline Sudan & 161 & 43 & $26.7 \%$ & $2.72 \%$ \\
\hline Cambodia & 61 & 25 & $41.0 \%$ & $1.58 \%$ \\
\hline Singapore & 35 & 23 & $65.7 \%$ & $1.45 \%$ \\
\hline Afghanistan & 51 & 22 & $43.1 \%$ & $1.39 \%$ \\
\hline Thailand & 70 & 17 & $24.3 \%$ & $1.08 \%$ \\
\hline Indonesia & 48 & 16 & $33.3 \%$ & $1.01 \%$ \\
\hline Somalia & 19 & 11 & $57.9 \%$ & $0.70 \%$ \\
\hline
\end{tabular}

CHB: chronic hepatitis B.

a For the purposes of the name list derivation, Chinese names included those born in the People's Republic of China, Taiwan and Hong Kong, and Korean names included both the Republic (South) and Democratic People's Republic (North).

b Suppressed for people born in Japan due to low numbers and excluded from name list total.

The use of surveillance data in this analysis provided a very large sample of over 33,000 notifications, resulting in narrow confidence intervals around sensitivity and specificity estimates as well as substantial power to detect differences over time and between subgroups.

It is difficult to ascertain what proportion of diagnosed cases are notified to health authorities, or if this varies according to disease, clinic, or patient demographics, but reporting is a legal requirement and compliance is thought to be reasonably high, particularly for laboratories [27]. However, relying on passive surveillance data limited control over quality and completeness, demonstrated by the high proportion of notifications with no country of birth reported, limiting sub-analysis by country. The finding that records without a specified country of birth were more likely to match the name list may also indicate a bias in non-reporting towards those from Asia-Pacific countries.

This validation study also necessarily limited evaluation of the screening value of the name list to those who have already been identified and diagnosed, and therefore the results may not be generalisable to the undiagnosed population that the screening test would be applied to. The evidence of differences in name list sensitivity according to demographic factors such as age and specific country of birth indicate that the effectiveness of the name list screening tool is dependent on the characteristics of the population.

In addition, other analyses of notifications data in Victoria have shown that a notable proportion of diagnoses arise from targeted testing programmes (such as antenatal and humanitarian migrant screening), which may be associated with birth in countries on the name list and affect resultant sensitivity estimates. The effect of targeted screening programmes on the representativeness of notification data has been observed previously, with women aged 20 to 29 years and migrants from countries such as Sudan and Burma (Myanmar) making up a greater than expected proportion of $\mathrm{CHB}$ notifications in Victoria due to, respectively, antenatal and humanitarian entrant screening $[4,28]$. As the migrants from countries on the name list currently entering the country are not usually part of humanitarian migration streams, they are under-represented in notifications and therefore this may have underestimated the sensitivity of the name list in detecting the population with CHB. The higher sensitivity of the name list for those born in China and Vietnam, observed here and in other studies $[17,19]$, is particularly valuable, as 
TABLE 4

Country of birth recording of chronic hepatitis B and salmonellosis cases according to demographic factors and presence of name list match (for all notifications), Victoria, 2001-2010 $(n=32,303)$

\begin{tabular}{|c|c|c|c|}
\hline & \multicolumn{2}{|c|}{ Country of birth recorded } & \multirow{2}{*}{$\mathrm{p}$ value } \\
\hline & Yes & No & \\
\hline $\begin{array}{l}\text { Age in years, median } \\
\text { (IQR) }\end{array}$ & $29(21-41)$ & $32(22-46)$ & $<0.001$ \\
\hline$\%$ male & $53.5 \%$ & $52.5 \%$ & 0.133 \\
\hline $\begin{array}{l}\% \text { matching name list } \\
\text { (either given name or } \\
\text { surname) }\end{array}$ & $32.7 \%$ & $39.5 \%$ & $<0.001$ \\
\hline TOTAL & 6,378 & 27,114 & \\
\hline
\end{tabular}

IQR: interquartile range.

people born in these two countries combined represent more than a third of people living with CHB in Australia $[13,28]$ and a substantial proportion of migrants with CHB in other settings [29].

The screening test construct used here is also limited by the categorisation of salmonellosis notifications as those without disease, when in fact these people may have undiagnosed CHB. However, given that the majority of notifications for salmonellosis occurred among those born in Australia and among young children, the prevalence of undiagnosed $\mathrm{CHB}$ in this population is likely to be considerably lower than in the general population (e.g. less than $1 \%$ ) [3] and would therefore not have a had a substantial effect on estimates of sensitivity and specificity.

Much of the difference in name list sensitivity according to age can be explained by the differing migration and demographic patterns according to country of birth. Those born in Asian countries made up a much smaller proportion of notifications in those aged o to 9 years compared with other regions of birth. In addition, migrants from the Middle East/North Africa and SubSaharan Africa regions are more likely to be younger than 15 years than those from Asian countries [26]. The name list may also be identifying younger people with Asian names who were born in Australia and whose risk of CHB may be lower, particularly since the implementation of universal infant vaccination.

This analysis is the first to investigate the validity of the name list to identify CHB cases in an Australian setting. The name list may have the potential for application in other countries where migrants born in Asia experience a disproportionate burden of $\mathrm{CHB}$, and this validation process could be carried out in jurisdictions with similar communicable disease surveillance systems. These results support the application of this name list predictive tool in general practice management software to trigger testing, an initiative that is currently being piloted in practices in Melbourne, Victoria situated in areas identified with a high prevalence of CHB [25]. The higher PPV of the name list as a screening tool when applied in higher prevalence populations suggests that practices serving communities with a higher burden of CHB would be optimal sites for implementing this approach.

The use of computer programmes to trigger testing in primary care based on patient characteristics has been shown to be effective in various contexts $[30,31]$ and may be particularly effective in this case, given the need expressed by Australian clinicians for improved knowledge about HBV, particularly regarding whom to test $[32,33]$. The results of this pilot project will allow assessment of the practical utility of the name list as a screening tool, and estimation of the sensitivity of the list in a previously untested clinical cohort, as opposed to a surveillance registry of people known to be infected. Post-implementation assessment could also provide the opportunity for improvement such as variation of match algorithm to balance sensitivity and specificity, or expansion to other countries.

The implementation of this screening in primary care settings with high CHB prevalence could help to improve access to preventive care, which is particularly imperative given the generally lower uptake of these programmes (for example cancer screening) among Australia's migrant populations [34,35]. Supporting improved delivery of primary care-based opportunistic testing also minimises the potential for stigmatisation of minority groups that could result from broader public campaigns highlighting their increased risk of a chronic infectious disease.

Despite differences in the migration patterns between the United States (where the name list was developed) and Australia, the six ethnicities represented in the list make up $65 \%$ of the total Asian-born population of Victoria [2], and estimates put the total burden of chronic hepatitis B in migrants from the name list countries at 60,000 to 100,000 people nationally $[13,28]$. However, there is still potential for inclusion of a more complete selection of countries that people living with CHB in Australia have migrated from, such as Thailand, Fiji and Indonesia $[4,13]$. This novel screening concept could also be applied to other diseases (communicable and non-communicable) that are associated with country of birth or ethnicity, possibly involving the development of name lists for other regions.

Systematically increasing diagnostic testing through the application of any screening process, including this name list, must consider the cost-effectiveness of doing so. There has been increasing evidence that screening and appropriate treatment for CHB is costeffective; a recent study from the United States [36] 
found that routine screening for CHB may be costeffective down to prevalence levels as low as $0.3 \%$. This is lower than the average Australian prevalence of $1.02 \%$ [3], and substantially lower than the prevalence of CHB in several parts of Melbourne [25].

In conclusion, the name list evaluated here shows potential as a screening tool to trigger testing of at-risk patients for HBV in primary care situations, being associated with CHB notifications and identifying a considerable proportion of those diagnosed. Although the links between name and country of birth, and country of birth and disease risk have been individually established, this analysis bridges the gap by clarifying the direct association between name and disease, a finding that may have relevance for public health screening initiatives in the future.

\section{Acknowledgements}

The authors wish to acknowledge the contribution of Ellen Donnan and Trevor Lauer, Department of Health Victoria, who extracted and de-identified the surveillance notifications for comparison with the name list.

Prof. Dallas English provided helpful comments on analytical methods for an earlier version of this paper, which was produced as part of a thesis for the Master of Science (Epidemiology) degree at the University of Melbourne.

\section{Conflict of interest}

YJW was a member of the Adult Hepatitis B Advisory Board for GlaxoSmithKline Australia and Bristol-Myers Squibb.

\section{References}

1. Lavanchy D. Hepatitis B virus epidemiology, disease burden, treatment, and current and emerging prevention and control measures. J. Viral Hepat. 2004;11(2):97-107. http://dx.doi.org/10.1046/j.1365-2893.2003.00487.x PMid:14996343

2. Australian Bureau of Statistics (ABS). Victoria: Country of birth of person by sex, 2006. Canberra: ABS; 2007.

3. MacLachlan JH, Allard N, Towell V, Cowie BC. The burden of chronic hepatitis B virus infection in Australia, 2011. Aust N Z J Public Health. 2013;37(5):416-22.

http://dx.doi.org/10.1111/1753-6405.12049

PMid:24090323

4. Williams S, Vally H, Fielding J, Cowie B. Chronic hepatitis B surveillance in Victoria, 1998-2008: instituting a 21st century approach to an old disease. Aust N Z J Public Health. 2011;35(1):16-21.

http://dx.doi.org/10.1111/j.1753-6405.2010.00611.x PMid:21299695

5. Lok ASF, McMahon BJ. Chronic hepatitis B: update 2009. Hepatology. 2009;50(3):661-2 http://dx.doi.org/10.1002/hep.23190 PMid:19714720

6. Papatheodoridis GV, Lampertico P, Manolakopoulos S, Lok A. Incidence of hepatocellular carcinoma in chronic hepatitis $B$ patients receiving nucleos(t)ide therapy: a systematic review. J Hepatol. 2010;53(2):348-56.

http://dx.doi.org/10.1016/j.jhep.2010.02.035

PMid:20483498

7. Asia-Pacific Working Party on Prevention of Hepatocellular Carcinoma. Prevention of hepatocellular carcinoma in the Asia-Pacific region: Consensus statements. J Gastroenterol Hepatol. 2010;25(4):657-63. http://dx.doi.org/10.1111/j.1440-1746.2009.06167.x PMid:20492323

8. Robotin MC, Kansil M, Howard K, George J, Tipper S, Dore $\mathrm{GJ}$, et al. Antiviral therapy for hepatitis B-related liver cancer prevention is more cost-effective than cancer screening. J Hepatol. 2009;50(5):990-8.

http://dx.doi.org/10.1016/j.jhep.2008.12.022

PMid:19303657

9. Veldhuijzen IK, Toy M, Hahné SJM, De Wit GA, Schalm SW, de Man RA, et al. Screening and early treatment of migrants for chronic hepatitis B virus infection is cost-effective. Gastroenterology. 2010;138(2):522-30. http://dx.doi.org/10.1053/j.gastro.2009.10.039 PMid:19879275

10. Weinbaum CM, Williams I, Mast EE, Wang SA, Finelli L, Wasley $A$, et al. Recommendations for identification and public health management of persons with chronic hepatitis B virus infection. Centers for Disease Control and Prevention: MMWR Recomm Rep. 2008;57(RR-8):1-20.

11. Cohen C, Evans AA, London WT, Block J, Conti M, Block T. Underestimation of chronic hepatitis $B$ virus infection in the United States of America. J Viral Hepat. 2008;15(1):12-3. PMid:18088239 PMCid:PMC2229201

12. Vyas $M$, Rohde S. Bridging the gap between viral hepatitis and liver cancer: policy recommendations of the European expert group for better control of liver cancer by optimally managing viral hepatitis. Brussels: Rohde Public Policy; 2012.

13. National Hepatitis B Strategy 2010 - 2013. Canberra: Australian Government Department of Health and Ageing; 2010. Available from: http://www.health.gov.au/internet/main/publishing.nsf/ Content/ohp-national-strategies-2010-hepb/\$File/hepb.pdf

14. Dev A, Nguyen J, Munafo L, Hardie E, Iacono L. Chronic hepatitis B - a clinical audit of GP management. Aust Fam Physician. 2011;40(7):533-8. PMid:21743864

15. National hepatitis B testing policy. Canberra: Australian Government Department of Health and Ageing; 2012. Available from: http://testing portal.ashm.org.au/resources/HBV/HBV_ TESTING POLICY FORMATTED V1.1_PRINT.pdf

16. Word DL, Perkins RC, Division USB of the CP. Building a Spanish Surname List for the 1990's: A New Approach to an Old Problem. Population Division, Washington: United States Census Bureau; 1996.

17. Lauderdale DS, Kestenbaum B. Asian American Ethnic Identification by Surname. Popul Res Policy Rev. 2000;19(3):283-300. http://dx.doi.org/10.1023/A:1026582308352

18. Nanchahal K, Mangtani P, Alston M, dos Santos Silva I. Development and validation of a computerized South Asian Names and Group Recognition Algorithm (SANGRA) for use in British health-related studies. J Public Health Med. 2001;23(4):278-85.

http://dx.doi.org/10.1093/pubmed/23.4.278

PMid:11873889 
19. Wong EC, Palaniappan LP, Lauderdale DS. Using name lists to infer Asian racial/ethnic subgroups in the healthcare setting. Med Care. 2010;48(6):540-6.

http://dx.doi.org/10.1097/MLR.obo13e3181d559e9

PMid:20421828 PMCid:PMC3249427

20. Hahne S, Ramsay M, Balogun K, Edmunds WJ, Mortimer P. Incidence and routes of transmission of hepatitis $B$ virus in England and Wales, 1995-2000: implications for immunisation policy. J Clin Virol. 2004;29(4):211-20.

http://dx.doi.org/10.1016/j.jcv.2003.09.016

PMid:15018847

21. Ryan R, Vernon S, Lawrence G, Wilson S. Use of name recognition software, census data and multiple imputation to predict missing data on ethnicity: application to cancer registry records. BMC Med Inform Decis Mak. 2012;12:3. http://dx.doi.org/10.1186/1472-6947-12-3 PMid:22269985 PMCid:PMC3353229

22. Hepatitis B. In: Blue Book. Victoria: Department of Health. [Accessed 12 Sep 2011]. Available from: http://ideas.health.vic. gov.au/bluebook/hepatitis-b.asp

23. Australian national notifiable diseases case definitions hepatitis B (unspecified). Canberra: Australian Government Department of Health and Ageing. [Accessed 18 Nov 2013]. Available from: http://www.health.gov.au/internet/main/ publishing.nsf/content/cda-surveil-nndss-casedefs-cd hepbun.htm

24. Salmonellosis. In: Blue Book. Victoria: Department of Health. [Accessed 12 Jul 2012]. Available from: http://ideas.health.vic. gov.au/bluebook/salmonellosis.asp

25. Cowie B, Karapanagiotidis T, Enriquez A, Kelly H. Markers of hepatitis $B$ virus infection and immunity in Victoria, Australia, 1995 to 2005 . Aust N Z J Public Health. 2010;34(1):72-8. http://dx.doi.org/10.1111/j.1753-6405.2010.00477.x PMid:20920109

26. Australian Bureau of Statistics (ABS). Victoria: Country of birth (major groups) by age and sex, 2006. Canberra: ABS; 2007.

27. Fielding J. Infectious diseases notification trends and practices in Victoria, 2009. Victorian Infectious Diseases Bulletin. 2010;13(3):85-90. Available from: http://docs. health.vic.gov. au/docs/doc/231C2E6AA5C657F4CA2578C4000C7B42/\$FILE/ VIDB-13-3-web.pdfe

28. Cowie B. The linguistic demography of Australians living with chronic hepatitis B. Aust N Z J Public Health. 2011;35(1):12-5. http://dx.doi.org/10.1111/j.1753-6405.2010.00634.x PMid:21299694

29. Kowdley KV, Wang CC, Welch S, Roberts H, Brosgart CL. Prevalence of chronic hepatitis $B$ among foreign-born persons living in the United States by country of origin. Hepatology. 2012;56(2):422-33. http://dx.doi.org/10.1002/hep.24804 PMid:22105832

30. Walker J, Fairley CK, Walker SM, Gurrin LC, Gunn JM, Pirotta $\mathrm{MV}$, et al. Computer reminders for Chlamydia screening in general practice: a randomized controlled trial. Sex Transm Dis. 2010;37(7):445-50. PMid:20375930

31. Shojania KG, Jennings A, Mayhew A, Ramsay CR, Eccles MP, Grimshaw J. The effects of on-screen, point of care computer reminders on processes and outcomes of care. Cochrane Database Syst Rev. 2009;(3):CDo01096. PMid:19588323

32. Wallace J, McNally S, Richmond J, Hajarizadeh B, Pitts $M$. Challenges to the effective delivery of health care to people with chronic hepatitis B in Australia. Sex Health. 2012;9(2):131-7. PMid:22498156

33. Guirgis M, Yan K, Bu YM, Zekry A. A study into general practitioners' knowledge and management of viral hepatitis in the migrant population. Intern Med J. 2012;42(5):497-504. http://dx.doi.org/10.1111/j.1445-5994.2011.02440.x PMid:21299780

34. Anikeeva O, Bi P, Hiller JE, Ryan P, Roder D, Han G-S. The health status of migrants in Australia: a review. Asia Pac J Public Health. 2010;22(2):159-93.

http://dx.doi.org/10.1177/1010539509358193 PMid:20457648

35. Weber MF, Banks E, Smith DP, O'Connell D, Sitas F. Cancer screening among migrants in an Australian cohort; crosssectional analyses from the 45 and Up Study. BMC Public Health. 2009;9:144. http://dx.doi.org/10.1186/1471-2458-9-144 PMid:19442312 PMCid:PMC 2693134

36. Eckman MH, Kaiser TE, Sherman KE. The cost-effectiveness of screening for chronic hepatitis B infection in the United States. Clin Infect Dis. 2011;52(11):1294-306.

http://dx.doi.org/10.1093/cid/cir199

PMid:21540206 PMCid:PMC3097367 